\title{
Reproducibility and relative validity of the short questionnaire to assess health-enhancing physical activity
}

Citation for published version (APA):

Wendel-Vos, G. C., Schuit, A. J., Saris, W. H. M., \& Kromhout, D. (2003). Reproducibility and relative validity of the short questionnaire to assess health-enhancing physical activity. Journal of Clinical Epidemiology, 56(12), 1163-1169. https://doi.org/10.1016/S0895-4356(03)00220-8

Document status and date:

Published: 01/01/2003

DOI:

10.1016/S0895-4356(03)00220-8

Document Version:

Publisher's PDF, also known as Version of record

\section{Please check the document version of this publication:}

- A submitted manuscript is the version of the article upon submission and before peer-review. There can be important differences between the submitted version and the official published version of record.

People interested in the research are advised to contact the author for the final version of the publication, or visit the DOI to the publisher's website.

- The final author version and the galley proof are versions of the publication after peer review.

- The final published version features the final layout of the paper including the volume, issue and page numbers.

Link to publication

\footnotetext{
General rights rights.

- You may freely distribute the URL identifying the publication in the public portal. please follow below link for the End User Agreement:

www.umlib.nl/taverne-license

Take down policy

If you believe that this document breaches copyright please contact us at:

repository@maastrichtuniversity.nl

providing details and we will investigate your claim.
}

Copyright and moral rights for the publications made accessible in the public portal are retained by the authors and/or other copyright owners and it is a condition of accessing publications that users recognise and abide by the legal requirements associated with these

- Users may download and print one copy of any publication from the public portal for the purpose of private study or research.

- You may not further distribute the material or use it for any profit-making activity or commercial gain

If the publication is distributed under the terms of Article $25 \mathrm{fa}$ of the Dutch Copyright Act, indicated by the "Taverne" license above, 


\title{
Reproducibility and relative validity of the Short Questionnaire to Assess Health-enhancing physical activity
}

\author{
G.C. Wanda Wendel-Vos ${ }^{\mathrm{a}, \mathrm{b}, *}$, A. Jantine Schuit ${ }^{\mathrm{a}}$, Wim H.M. Saris ${ }^{\mathrm{c}}$, Daan Kromhout ${ }^{\mathrm{a}, \mathrm{b}}$ \\ ${ }^{a}$ Department for Chronic Diseases Epidemiology, National Institute for Public Health and the Environment, \\ P.O. Box 1, 3720 BA Bilthoven, The Netherlands \\ ${ }^{\mathrm{b}}$ Division of Human Nutrition and Epidemiology, Wageningen University, P.O. Box 8129, 6700 EV, Wageningen, The Netherlands \\ ${ }^{\mathrm{c}}$ Nutrition and Toxicology Research Institute (NUTRIM), Maastricht University, P.O. Box 616, 6200 MD, Masstricht, The Netherlands
}

Accepted 15 May 2002

\begin{abstract}
Objective: The purpose of this study is to determine reproducibility and relative validity of the Short $Q U$ estionnaire to ASsess Healthenhancing physical activity (SQUASH).

Methods: Participants (36 men and 14 women, aged 27-58) were asked to complete the SQUASH twice with an inbetween period of approximately 5 weeks. In addition, participants wore the Computer Science and Applications (CSA) Activity Monitor for a 2-week period following the first questionnaire.

Results: The Spearman correlation for overall reproducibility of the SQUASH was 0.58 (95\%-CI 0.36-0.74). Correlations for the reproducibility of the separate questions varied between 0.44 and 0.96 . Spearman's correlation coefficient between CSA readings and the total activity score was 0.45 (95\%-CI $0.17-0.66)$.

Conclusion: In conclusion, the SQUASH is a fairly reliable and reasonably valid questionnaire and may be used to order subjects according to their level of physical activity in an adult population. Because the SQUASH is a short and simple questionnaire, it may proof to be a very useful tool for the evaluation of health enhancing physical activity in large populations. (C) 2003 Elsevier Inc. All rights reserved.
\end{abstract}

Keywords: Reproducibility; Relative validity; Questionnaire; Physical activity; Accelerometer; Guideline

\section{Introduction}

Epidemiologic studies often use questionnaires to assess physical activity levels, because it is an inexpensive and generally useful tool in categorizing subjects in high and low levels of physical activity. In addition, questionnaires are relatively easy to administer and generally acceptable to study participants $[1,2]$. Consequently, self-report questionnaires remain the most commonly used method of assessing physical activity [3]. However, because statistics on physical activity depend on the questionnaire used to assess physical activity, it is often not possible to compare results of population studies. Especially for national and regional health institutes, this constitutes a definite need to standardize measures of physical activity $[1,3]$.

Following the Americans, Dutch physical activity experts reached consensus about a physical activity guideline,

\footnotetext{
* Corresponding author. Tel.: +31-(0)30-274-3321; fax: +31-(0)30274-4407.

E-mail address: Wanda.Vos@rivm.nl (G.C.W. Wendel-Vos).
}

which states that every adult should accumulate $30 \mathrm{~min}$ or more of moderate intense physical activity ( $\geqslant 4$ MET) on most, preferably all days of the week. Most of the frequently used physical activity questionnaires like the Baecke [4,5], the EPIC [6], and the Voorrips questionnaire [7] are not designed to estimate compliance to this guideline.

Therefore, the Dutch National Institute of Public Health and the Environment developed a Short QUestionnaire to $A S$ sess Health-enhancing physical activity (SQUASH). The basic assumption for the questionnaire was that it should (a) be reproducible and valid, (b) be short (less than $5 \mathrm{~min}$ to fill in), and (c) contain questions on habitual activities with respect to occupation, leisure time, household, transportation means, and other daily activities.

It should be noted that the questionnaire was not designed to measure energy expenditure, but to give an indication of the habitual activity level. The SQUASH was structured in such a way that it would be possible to assess compliance to physical activity guidelines.

The aim of this study was to investigate reproducibility and relative validity of the SQUASH in measuring the habitual activity level of a population. 


\section{Methods}

\subsection{Study population}

Participants were recruited from a commercial bank in the cities of Arnhem and Zoetermeer in The Netherlands. The age range of the source population was 18-65 years of age. Recruitment took place in July and August 1999. The aim was to recruit 60 participants, equally divided over men and women. Of the eligible source population 55 employees voluntary applied for the study. Of these, five men withdrew from the study because of time restraints. Eventually, 50 subjects (36 men and 14 women) were enrolled. All subjects signed an informed consent form. The study was executed during the summer season with no large fluctuations in weather conditions.

\subsection{Study design}

Participants were submitted to a physical examination and were asked to fill in the SQUASH. In addition to the SQUASH, some demographic questions were asked. During the following 2 weeks the participants wore the Computer Science and Applications (CSA), Inc. activity monitor, and they kept a diary in which periods of noncompliance to the CSA were noted. The SQUASH was administered for a second time after a period of approximately 5 weeks.

\subsubsection{Physical activity questionnaire}

Appendix A contains the SQUASH. Completing the SQUASH takes about 3-5 min (monitored during the first SQUASH measurement). To guide participants through the questionnaire, questions were prestructured in (A) commuting activities, (B) leisure time activities, (C) household activities, and (D) activities at work and school. To make it easier for subjects to know which type of activities were applicable, examples of activities were mentioned under sports, household activities, and activities at work. The choice of activities included in the SQUASH was based on their intensity ( $\geqslant 4$ MET), except for light household activities and light activities at work and school. These activities usually represent a considerable amount of time per day, and therefore, they contribute to the habitual activity level of a population. Hobbies were not included in the SQUASH. These activities often have very low MET values ( $<2 \mathrm{MET}$ ), and were therefore considered to contribute negligibly to habitual activity levels. Hobbies that do have meaningful MET values are often noted as sports.

The SQUASH consists of three main queries: days per week, average time per day, and intensity. Prestructuring in frequency and duration has proven to give more reliable results [2]. In parts (C) and (D), intensity was prestructured into two categories to keep the questionnaire short and easy to fill in. In part (D), the "days per week" query was omitted for the same reason. Moreover, it was assumed that participants are used to quantify their time at work and school in terms of hours per week.

\section{Appendix A: The short questionnaire to assess health enhancing physical activity (SQUASH)}

Think about an average week in the past months. Please indicate how many days per week you performed the following activities, how much time on average you were engaged in this, and (if applicable) how strenuous this activity was for you?

\begin{tabular}{|llll|}
\hline $\begin{array}{l}\text { COMMUTING } \\
\text { ACTIVITIES } \\
\text { (round trip) }\end{array}$ & $\begin{array}{l}\text { days } \\
\text { per } \text { week }\end{array}$ & $\begin{array}{l}\text { average } \\
\text { time per day }\end{array}$ & $\begin{array}{l}\text { Effort } \\
\text { (circle please) }\end{array}$ \\
$\begin{array}{c}\text { Walking to/from } \\
\text { work or school }\end{array}$ & days & hour minutes & slow/moderate/fast \\
$\begin{array}{c}\text { Bicycling to/from } \\
\text { work or school }\end{array}$ & days & hour minutes & slow/moderate/fast \\
Not applicable & & & \\
\hline
\end{tabular}

\begin{tabular}{|c|c|c|c|}
\hline $\begin{array}{l}\text { LEISURE TIME } \\
\text { ACTIVITIES }\end{array}$ & $\begin{array}{l}\text { days } \\
\text { per week }\end{array}$ & $\begin{array}{l}\text { average time } \\
\text { per day }\end{array}$ & $\begin{array}{l}\text { Effort } \\
\text { (circle please) }\end{array}$ \\
\hline Walking & days & hour minutes & $\begin{array}{l}\text { slow/moderate } \\
\text { /fast }\end{array}$ \\
\hline Bicycling & days & hour minutes & $\begin{array}{l}\text { slow/moderate } \\
\text { /fast }\end{array}$ \\
\hline Gardening & days & hour minutes & $\begin{array}{l}\text { light } / \text { moderate } \\
\text { /intense }\end{array}$ \\
\hline Odd jobs & days & hour minutes & $\begin{array}{l}\text { light } / \text { moderate } \\
\text { /intense }\end{array}$ \\
\hline $\begin{array}{l}\text { Sports (please write } \\
\text { down yourself) } \\
\text { e.g., tennis, fitness, } \\
\text { skating, swimming, } \\
\text { dancing }\end{array}$ & & & \\
\hline 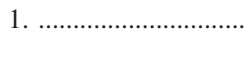 & days & hour minutes & $\begin{array}{l}\text { light/moderate } \\
\text { /intense }\end{array}$ \\
\hline 2. (n.......................... & days & hour minutes & $\begin{array}{l}\text { light/moderate } \\
\text { /intense }\end{array}$ \\
\hline 3. & days & hour minutes & $\begin{array}{l}\text { light/moderate } \\
\text { /intense }\end{array}$ \\
\hline 4. . & days & hour minutes & $\begin{array}{l}\text { light } / \text { moderate } \\
\text { /intense }\end{array}$ \\
\hline
\end{tabular}

\begin{tabular}{|lll|}
\hline HOUSEHOLD ACTIVITIES & days per week & average time per day \\
Light household work & days & hour minutes \\
(cooking, washing dishes, & days & hour minutes \\
$\quad$ ironing, child care) & & \\
Intense household work & & \\
(scrubbing floor, walking & & \\
$\quad$ with heavy shopping bags) & &
\end{tabular}

\section{ACTIVITY AT WORK}

AND SCHOOL

average time

Light work per week

(sitting/standing with some walking, e.g., a desk job) hour minutes Intense work

(regularly lifting heavy objects at work)

Not applicable

All 50 subjects completed the SQUASH twice. They were asked to refer to an average week in the past months. Between the first and second SQUASH measurement there was a period of approximately 5 weeks. This period was 
thought to be long enough to ensure that participants could not copy the SQUASH from memory and short enough to prevent large changes in physical activity levels. The SQUASH was checked for completeness by the researcher. If applicable, missing answers were added later to the questionnaire, after consulting the subjects.

\subsubsection{Calculating the activity score per week from the questionnaire}

Activities were subdivided into three intensity categories: 2 to $<4.0 \mathrm{MET}$ (light), 4.0 to $<6.5 \mathrm{MET}$ (moderate), and $\geqslant$ 6.5 MET (vigorous) with the help of Ainsworth's compendium of Physical activities [8]. Activities with a MET value lower than 2 MET were not included in the SQUASH for reasons mentioned earlier. Cutoff points for intensity categories were based on the Dutch physical activity guideline [9]. Based on the reported effort in the questionnaire, activities were given an intensity score (ranging from 1 to 9) as depicted in Table 1. For example: bicycling received an intensity score of either 4, 5, or 6 based on reported effort being slow, moderate, or fast, respectively. For walking, these intensity scores were 1, 2, and 3. Household work and activities at work or school were prestructured for intensity. Therefore, for these items we used a basic intensity score of 2 and 5 for light and intense activities, respectively. Total minutes of activity were calculated for each question by multiplying frequency (days/week) by duration (min/day). Activity scores for separate questions were calculated by multiplying total minutes of activity by the intensity score. The total activity score was calculated by taking the sum of the activity scores for separate questions.

Table 1

Intensity scores used for calculation of the SQUASH activity scores

\begin{tabular}{|c|c|c|c|}
\hline & \multicolumn{3}{|c|}{ Intensity scores based on reported effort ${ }^{\mathrm{a}}$} \\
\hline & Light & Moderate & Intense \\
\hline \multicolumn{4}{|l|}{ Commuting activities } \\
\hline $\begin{array}{l}\text { Walking to/from work } \\
\text { or school }\end{array}$ & 1 & 2 & 3 \\
\hline $\begin{array}{l}\text { Bicycling to/from work } \\
\text { or school }\end{array}$ & 4 & 5 & 6 \\
\hline \multicolumn{4}{|l|}{ Leisure time activities } \\
\hline Walking & 1 & 2 & 3 \\
\hline Bicycling & 4 & 5 & 6 \\
\hline Gardening & 4 & 5 & 6 \\
\hline Odd jobs & 1 & 2 & 3 \\
\hline \multicolumn{4}{|l|}{ Sports } \\
\hline 2 to $<4 \mathrm{MET}$ & 1 & 2 & 3 \\
\hline 4 to $<6.5 \mathrm{MET}$ & 4 & 5 & 6 \\
\hline$\geqslant 6.5 \mathrm{MET}$ & 7 & 8 & 9 \\
\hline \multicolumn{4}{|l|}{ Household activities } \\
\hline Light household work & & 2 & \\
\hline Intense household work & & 5 & \\
\hline \multicolumn{4}{|l|}{ Activity at work and school } \\
\hline Light work & & 2 & \\
\hline Intense work & & 5 & \\
\hline
\end{tabular}

a Intensity scores $\geqslant 3$ were assumed to represent health-enhancing physical activity.

\subsubsection{Activity monitor}

In the present study we used the CSA Inc. Activity Monitor (model AM7164-2.2), which is a small $(5.1 \times 3.8 \times 1.5$ $\mathrm{cm}$ ), lightweight (45 g), single-channel accelerometer. This accelerometer was designed to measure and record time varying accelerations ranging in magnitude from approximately 0.05 to two times gravitational acceleration. The activity monitor is band limited with a frequency response from 0.25 to 2.5 Hertz. Operating this way, the monitor detects normal human motions and rejects motions from other sources [10].

Data were collected for each minute, beginning at the time the monitor was programmed to start and finishing at the time the monitor was manually stopped by the researcher. The data collected by the activity monitor are counts per minute representing the intensity of activity in each minute.

Participants were instructed to wear the monitor for a period of 2 weeks during the time they were not asleep, except for swimming and showering. Placement of the monitor was attached to a belt on the waist (sagital line), the notch on the case pointing upward. Participants were instructed to keep the monitor snugly against the body so it was not allowed to flop around.

\subsubsection{Calculating activity counts per minute from the activity monitor}

Total activity counts per minute were calculated by dividing the total activity count over 2 weeks by the total number of minutes that the monitor was worn. Cutoff points for the intensity groups were consistent with those of the SQUASH (2, 4, and 6.5 MET). Activity counts were converted to MET values using the equation published by Freedson et al. [11].

For the purpose of reproducibility of this reference method, the activity level was only calculated for days on which the monitor was worn for $12 \mathrm{hr}$ or longer. Assuming one sleeps for $8 \mathrm{hr}$ a day, collecting data for a minimum of $12 \mathrm{hr}$ represents at least $75 \%$ of the available time (16 hr) per day. Furthermore, the monitor had to be worn for at least 7 days, because of comparability to the SQUASH reference period. As a consequence, valid CSA data were available for 37 participants (26 men and 11 women). The main reason for participants not to wear the CSA was forgetting to wear it. In only one subject we encountered a technical problem; one of the belt notches broke off, which made that accelerometer unusable.

\subsubsection{Physical examination}

The physical examination consisted of measurement of height, weight, waist circumference, blood pressure, and the submaximal Astrand test (aerobe fitness test). Height was measured to the nearest $0.5 \mathrm{~cm}$ without shoes, while weight was measured to the nearest $0.5 \mathrm{~kg}$ in subjects wearing indoor clothing and no shoes, after they had emptied their pockets. Waist circumference was measured with a tape measure in the middle between the bottom of the lower rib and the top of the pelvis. Blood pressure was measured 
with a fully automatic sphygometer (Omron 711, Omron Healthcare Europe B.V., Hoofddorp, The Netherlands). The submaximal Astrand test [12] was executed with a mechanically braked bicycle ergometer (Monark). The purpose of this test is to estimate physical fitness by predicting maximal oxygen consumption. The predicted maximal oxygen consumption is based upon the steady-state heart rate of a person exercising at a submaximal power level for $6 \mathrm{~min}$. These measures were used to characterise the study population.

\subsection{Statistical analysis}

Reproducibility of the SQUASH was examined by calculating Spearman's correlation coefficient between the total activity scores from both administrations (overall and separate for each activity). We hypothesised that reproducibility of the SQUASH lies within the upper range of reproducibility of other questionnaires (correlation coefficient between 0.37 and 0.92).

Overall relative validity was investigated by assessing Spearman's correlation coefficient between the total activity score of the first SQUASH administration and the counts per minute of the CSA. We used the first SQUASH administration to (a) avoid a possible bias caused by increased awareness of activity as a result of wearing a CSA, and (b) to exclude the possibility of bias as a result of a learning effect. Validity of the SQUASH should be within the upper range of validity (Spearman correlation coefficient between 0.32 and 0.45 ) of other questionnaires validated with accelerometers. The aimed size of our study population $(n=60)$ was calculated to be sufficient to find a significant correlation coefficient of at least 0.43 . In addition to the overall relative validity, the ability of the SQUASH regarding categorizing subjects according to their physical activity level was examined. For this purpose the kappa statistic was calculated for the tertiles of both activity scores and activity counts. Kappa values of 0.4 and higher are assumed to represent fair to good agreement. For the same purpose we calculated the $\%$ exact agreement between tertiles. An exact agreement of $50 \%$ or higher is assumed to represent fair agreement.

\section{Results}

The average age of the study population was 44 years and about $70 \%$ were men. Approximately two-thirds of the study population had a primary or lower vocational education. Approximately 50\% of the study population had a good, high, or very high fitness (Table 2).

According to the SQUASH $84 \%$ of the total minutes of activity per week was spent in the intensity category 2 to $<4$ MET, whereas according to CSA readings $91 \%$ of registered time was spent in this category. The mean absolute amount of time spent in all three intensity categories was consistently higher for the SQUASH than for the CSA (see Table 2).
Table 2

Characteristics (mean $\pm \mathrm{SD}$ ) of the study population

\begin{tabular}{|c|c|c|c|}
\hline & $\begin{array}{l}\text { Total } \\
n=50\end{array}$ & $\begin{array}{l}\text { Men } \\
n=36\end{array}$ & $\begin{array}{l}\text { Women } \\
n=14\end{array}$ \\
\hline Age (years) & $44 \pm 6$ & $45 \pm 6$ & $41 \pm 7$ \\
\hline Height (m) & $1.75 \pm 0.10$ & $1.79 \pm 0.08$ & $1.64 \pm 0.09$ \\
\hline Weight $(\mathrm{kg})$ & $81.0 \pm 14.4$ & $85.6 \pm 12.6$ & $69.3 \pm 12.2$ \\
\hline Body Mass Index $\left(\mathrm{kg} / \mathrm{m}^{2}\right)$ & $26.3 \pm 3.9$ & $26.6 \pm 3.9$ & $25.6 \pm 3.9$ \\
\hline Waist circ $(\mathrm{cm})$ & $91.3 \pm 12.6$ & $95.5 \pm 11.1$ & $80.3 \pm 9.5$ \\
\hline Systolic bp (mmHg) & $127 \pm 17$ & $132 \pm 16$ & $117 \pm 13$ \\
\hline Diastolic bp (mmHg) & $83 \pm 10$ & $84 \pm 11$ & $79 \pm 7$ \\
\hline \multicolumn{4}{|l|}{ Fitness $(\%)^{\mathrm{a}}$} \\
\hline Low & 0 & 0 & 0 \\
\hline Fair & 12.0 & 13.9 & 7.1 \\
\hline Average & 40.0 & 44.4 & 28.6 \\
\hline Good & 38.0 & 27.8 & 64.3 \\
\hline High & 8.0 & 11.1 & 0 \\
\hline Very high & 2.0 & 2.8 & 0 \\
\hline \multicolumn{4}{|l|}{ Social economic status $(\%)^{\mathrm{b}}$} \\
\hline Low & 66 & 61 & 79 \\
\hline Medium & 10 & 11 & 7 \\
\hline High & 24 & 28 & 14 \\
\hline \multicolumn{4}{|l|}{ Physical activity (min/day) } \\
\hline \multicolumn{4}{|l|}{ SQUASH } \\
\hline 2-4 MET & $360 \pm 128$ & $370 \pm 138$ & $350 \pm 100$ \\
\hline 4-6.5 MET & $60 \pm 67$ & $63 \pm 66$ & $54 \pm 72$ \\
\hline$\geqslant 6.5 \mathrm{MET}$ & $10 \pm 24$ & $12 \pm 28$ & $2 \pm 5$ \\
\hline \multicolumn{4}{|l|}{ CSA } \\
\hline 2-4 MET & $120 \pm 40$ & $130 \pm 37$ & $109 \pm 43$ \\
\hline 4-6.5 MET & $10 \pm 10$ & $12 \pm 10$ & $5 \pm 6$ \\
\hline$\geqslant 6.5 \mathrm{MET}$ & $2 \pm 3$ & $3 \pm 4$ & $1 \pm 0.5$ \\
\hline
\end{tabular}

${ }^{\text {a }}$ Categories of fitness according to the submaximal Astrand bike test [12].

${ }^{\mathrm{b}}$ Social economic status is based on educational level: low $=$ lower vocational and primary, medium $=$ intermediate vocational and secondary, high $=$ higher vocational and university.

In total, $60 \%$ of the reported time concerned activities at work. Household activities took up $22 \%$ of the reported time. For leisure time and commuting activities this was 16 and $2 \%$, respectively (Table 3 ).

\subsection{Reproducibility}

Spearman's correlation coefficient for the total activity score was 0.58 . Reproducibility of the separate questions had a mean value of 0.75 (range: 0.44-0.96; Table 3). Intense household work was least reliable and commuting by bike was most reliable.

Reproducibility (Spearman's correlation coefficient) within the intensity categories ( 2 to $<4$ MET, 4 to $<6.5$ MET, and $\geqslant 6.5$ MET) was $0.58,0.54$, and 0.92 , respectively (not in table).

\subsection{Relative validity}

Spearman's correlation coefficient between the calculated activity levels from the SQUASH and the CSA was 0.45 $(P=.005$; 95\%-CI 0.17-0.66). When comparing tertiles of the activity score with tertiles of the activity counts, exact agreement was $46 \%$ and the weighed kappa was 0.30 (Fig. 1). 
Table 3

Mean (SD) amount of minutes per week, activity for the dual measurement, and reproducibility (Spearman correlation coefficient (95\%-CI))

\begin{tabular}{|c|c|c|c|c|}
\hline Item & $\begin{array}{l}\text { Minutes/week } \\
\text { SQUASH-I } \\
n=50\end{array}$ & $\begin{array}{l}\text { Activity score }^{\mathrm{a}} \\
\text { SQUASH-I } \\
n=50\end{array}$ & $\begin{array}{l}\text { Activity score }^{\mathrm{a}} \\
\text { SQUASH-II } \\
n=50\end{array}$ & $\begin{array}{l}\text { Repeatability } \\
r_{\text {Spearman }}(95 \%-\mathrm{CI}) \\
n=50\end{array}$ \\
\hline All items together & $3045(931)$ & $7787(3061)$ & $7912(3071)$ & $0.58 *(0.36-0.74)$ \\
\hline \multicolumn{5}{|l|}{ Commuting } \\
\hline Walking & $10(34)$ & $25(95)$ & $26(73)$ & $0.72 *(0.55-0.83)$ \\
\hline Bicycling & $45(71)$ & $224(357)$ & $223(367)$ & $0.96 *(0.94-0.98)$ \\
\hline \multicolumn{5}{|l|}{ Activities at work } \\
\hline Light & $1738(803)$ & 3475 (1606) & 3161 (1629) & $0.73 *(0.56-0.84)$ \\
\hline Intense & $89(341)$ & 445 (1704) & $661(2284)$ & $0.89 *(0.82-0.94)$ \\
\hline \multicolumn{5}{|l|}{ Household activities } \\
\hline Light & $618(644)$ & $1236(1288)$ & $1113(1165)$ & $0.74 *(0.59-0.85)$ \\
\hline Intense & $60(111)$ & $298(552)$ & 728 (1994) & $0.44 * *(0.18-0.64)$ \\
\hline \multicolumn{5}{|l|}{ Leisure time } \\
\hline Walking & 93 (178) & 209 (426) & $136(259)$ & $0.80 *(0.68-0.88)$ \\
\hline Bicycling & $69(120)$ & $369(684)$ & 355 (619) & $0.73 *(0.57-0.84)$ \\
\hline Gardening & $100(207)$ & 467 (977) & $478(817)$ & $0.68 *(0.50-0.81)$ \\
\hline Odd jobs & 80 (169) & $158(339)$ & $186(364)$ & $0.64 *(0.44-0.78)$ \\
\hline Sports & $143(254)$ & $881(1688)$ & 845 (1378) & $0.90 *(0.83-0.94)$ \\
\hline
\end{tabular}

$* P \leqslant .0001$.

$* * P \leqslant .001$.

${ }^{\text {a }}$ Activity score $=$ minutes $\times$ intensity.

\section{Discussion}

The SQUASH is a short physical activity questionnaire with the general purpose to assess habitual physical activity. Overall reproducibility of the SQUASH was $0.58(95 \%$-CI $0.36-0.74)$. High intense activities were more reliable than low intense activities. The SQUASH activity score was significantly correlated with the activity counts per minute measured by the CSA ( $r_{\text {Spearman }}=0.45,95 \%$-CI $\left.0.17-0.66\right)$. Consequently, the SQUASH is able to explain $4-49 \%$ of the total variation in physical activity. When comparing tertiles of activity scores with tertiles of activity counts, exact agreement was $46 \%$. This means that approximately half of the population was classified in the same tertile using either CSA or SQUASH. The kappa value of this comparison was 0.30 , which is rather low.

A few methodologic aspects of this study need to be considered. The study population consisted of relatively inactive but fit subjects. This might have influenced reproducibility and relative validity of the physical activity questionnaire, because light, often highly variable activities are the most difficult to recall [13]. The fact that we found a relatively low reproducibility of intense household work can be explained by the frequency of this type of activity. Today, few people spend a lot of time on intense household work on a regular basis, which probably results in a less accurate remembrance of frequency, duration, and intensity of this activity [13]. Also, the low percentage of women (who are the main performers of the housework) in our study population could have influenced repeatability of this item.

Reproducibility may also have been influenced by the study design in which the CSA was worn inbetween the two measurements of the SQUASH. This may have increased awareness about physical activity among participants during the second measurement. However, we belief this to be of minor influence because of three reasons. First, the CSA has no display, so subjects were not informed about their physical activity level. Second, the CSA is a lightweight (45 g) device that does not constantly remind subjects of wearing it. Third, the period between wearing the CSA and completing the SQUASH for the second time was at least 2 weeks, which makes it less plausible that participants were still better aware of their physical activity level. Nevertheless, if increased awareness did play a role during the second measurement it would have probably lead to underestimation of the reproducibility of the SQUASH.

Using the CSA as a reference method had some disadvantages. First, the CSA, unlike the doubly labeled water method, is not a golden standard for measurement of physical activity. Using the doubly labeled water method was not an option in this study, because of the costs involved and because it does not measure intensity of physical activity. Second, the CSA is not waterproof, and therefore cannot be worn during activities involving water, such as swimming, showering, and rowing. However, because these activities do not substantiate the majority of activities in a free-living population, one should be able to estimate the total physical activity level with the CSA. Third, the CSA is a oneaxial accelerometer for vertical movement. Consequent to wearing this type of activity monitor on the waist, activities such as bicycling and fitness may not be measured accurately, leading to a possible underestimation of the activity level by the CSA. However, leaving these activities out of the calculation of the activity score did not significantly alter the correlation coefficient between the total activity score 


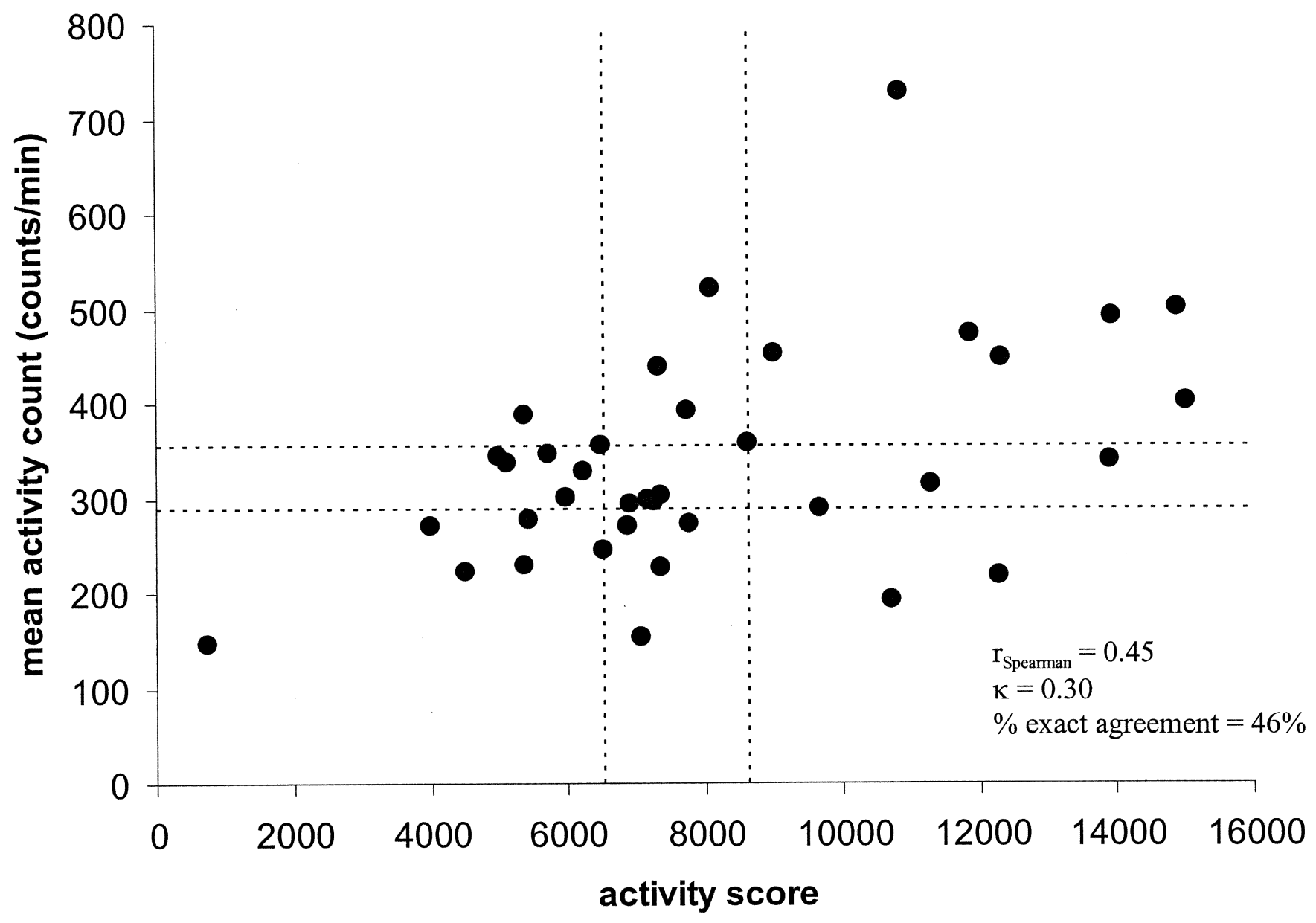

Fig. 1. Tertiles (dotted lines) of the activity score per week (SQUASH-I) and the mean activity counts per minute (CSA) representing relative validity of the SQUASH.

and the activity count per minute of the SQUASH. Fourth, the CSA clearly measured lower absolute activity levels (in $\mathrm{min} /$ day) than the SQUASH. Although our population was not very active, this difference also seems to represent an underestimation of activity by the activity monitor. A reason could be that the Freedson equation we used for transforming activity counts to MET values might not be valid in a population with a low level of physical activity. The equation was derived from data collected in a laboratory setting using a motorized treadmill and three types of exercise conditions (slow walking, fast walking, and jogging). The range of METS represented by these conditions was 3.7-9.7 METS. No data points were available for the 6.5-8 MET range [11]. More research might be needed to develop an equation that represents a wider range of activities, particularly for the lower MET values, possibly leading to a better estimate of absolute activity levels.

Reproducibility of physical activity questionnaires has been frequently determined in adults in the past [2]. Philippaerts et al. examined repeatability of three physical activity questionnaires and found kappa values varying from 0.61-0.70 [14]. Pols et al. found Spearman's correlation coefficients varying from $0.47-0.89$ in one study and 0.70 0.76 in another study $[6,15]$. In two other studies correlation coefficients were reported ranging from 0.37 to $0.92[16,17]$. In our reproducibility study we found correlation coefficients for the SQUASH varying from 0.44 to 0.96 for separate items of the questionnaire and a correlation coefficient of 0.58 for all items together. Reproducibility of the SQUASH is therefore comparable to other physical activity questionnaires. The SQUASH has some distinct advantages compared to other physical activity questionnaires, because it is short (only 1 page) and quick to fill in (3-5 min). Moreover, the SQUASH provides the opportunity to estimate compliance to physical activity guidelines.

Philippaerts et al. used the doubly labeled water method to validate three physical activity questionnaires in adults (Baecke, five-city questionnaire and an adapted version of the Tecumseh community health study questionnaire). They found Pearson correlation coefficients varying from 0.340.69 for total activity levels [18]. Miller et al. used Caltrac (one-axial accelerometer) readings of 26 adult subjects and compared these to activity levels of five questionnaires [7day recall $\left(r_{\text {Spearman }}=0.79\right), 3$-day recall $\left(r_{\text {Spearman }}=0.25\right)$, 
Godin $\left(r_{\text {Spearman }}=0.45\right)$, Baecke $\left(r_{\text {Spearman }}=0.40\right)$, and NASA $\left.\left(r_{\text {Spearman }}=0.32\right)\right][19]$. The Caltrac and the CSA were compared by Melanson et al. during walking, fast walking, and jogging on treadmill. The two instruments were found to be equally able to measure amount and intensity of physical activity. [20].

The correlation coefficient we found in our validation study of the SQUASH lies within the range of correlation coefficients found in the study by Miller et al. In that study the highest Spearman correlation coefficient was found for the 7-day recall method, which (together with the 3-day recall method used in that study), in principal, is a different method than the SQUASH. Comparing validity of the SQUASH with validity of the Godin, Baecke, and NASA questionnaire, it can be concluded that validity of the SQUASH lies within the upper range of validity found for other questionnaires that were validated with an accelerometer. Therefore, the correlation coefficient we found $\left[r_{\text {Spearman }}=0.45 ; 95 \%\right.$ CI (0.17-0.66)] for the SQUASH can be marked as reasonable and acceptable. Furthermore, our study population had a relatively sedentary lifestyle because the percentage $(58 \%$ vs. at least $45 \%$ ) of subjects not complying to the physical activity guideline was approximately $10 \%$ higher than in the general Dutch population [21]. This suggests that the overall relative validity of the SQUASH is acceptable for sedentary populations. Based on the assumption that more intense activities are usually easier to recall relative validity of the SQUASH may be higher in the general, more active population. However, this still needs to be further investigated.

In conclusion, the SQUASH is a fairly reliable and reasonably valid questionnaire, and may be used to order subjects according to their level of physical activity in an adult population. Because the SQUASH is a short and simple questionnaire, it may prove to be a very useful tool for the evaluation of health enhancing physical activity in large populations.

\section{References}

[1] U.S. Department of Health and Human Services. Physical activity and health; a report of the Surgeon General. Atlanta, GA: U.S.: Department of Health and Human Services, Centers for Disease Control and Prevention, National Center for Chronic Disease Prevention and Health Promotion; 1996.

[2] Montoye HJ, Kemper HG, Saris WHM, Washburn RA. Measuring physical activity and energy expenditure. Champaign (IL): Human Kinetics; 1996.
[3] Sarkin JA, Nichols JF, Sallis JF, Calfas KJ. Self-report measures and scoring protocols affect prevalence estimates of meeting physical activity guidelines. Med Sci Sports Exerc 2000;32(1):149-56.

[4] Pols MA, Peeters PH, Bueno-De-Mesquita HB, Ocke MC, WentinkCA, Kemper HC, Collette HJ. Validity and repeatability of a modified Baecke questionnaire on physical activity. Int J Epidemiol 1995;24(2): 381-8.

[5] Baecke JA, Burema J, Frijters JE. A short questionnaire for the measurement of habitual physical activity in epidemiological studies. Am J Clin Nutr 1982;36(5):936-42.

[6] Pols MA, Peeters PH, Ocke MC, Slimani N, Bueno-de-Mesquita $\mathrm{HB}$, Collette HJ. Estimation of reproducibility and relative validity of the questions included in the EPIC Physical Activity Questionnaire. Int J Epidemiol 1997;26(Suppl 1):S181-9.

[7] Voorrips LE, Ravelli AC, Dongelmans PC, Deurenberg P, Van Staveren WA. A physical activity questionnaire for the elderly. Med Sci Sports Exerc 1991;23(8):974-9.

[8] Ainsworth BE, Haskell WL, Leon AS, Jacobs DR, Montoye HJ, Sallis JF, Paffenbarger RS. Compendium of physical activities: classification of energy costs of human physical activities. Med Sci Sports Exerc 1993;25(1):71-80.

[9] Hildebrandt VH, Ooijendijk WTM, Stiggelbout M. Trendrapport bewegen en gezondheid 1998/1999. Lelystad, NL: Koninklijke vermande; 1999. p. 23-9.

[10] Computer Science and Applications Inc. Activity monitor operator's manual; model 7164; version AM7164-2.2. Shalimar (FL): Computer Science and Applications Inc, Ambulatory Monitoring Applications Division; 1999. p. 2.

[11] Freedson PS, Melanson E, Sirard J. Calibration of the Computer Science and Applications, Inc. accelerometer. Med Sci Sports Exerc 1998;30(5):777-81.

[12] Astrand PO. Work tests with the bicycle ergometer. Varberg, Sweden: Monark Crescent AB; 1988. p. 110-23.

[13] Jacobs DR, Ainsworth BE, Hartman TJ, Leon AS. A simultaneous evaluation of 10 commonly used physical activity questionnaires. Med Sci Sports Exerc 1993;25(1):81-91.

[14] Philippaerts RM, Lefevre J. Reliability and validity of three physical activity questionnaires in Flemish males. Am J Epidemiol 1998;147(10): 982-90.

[15] Pols MA, Peeters PH, Ocke MC, Bueno-de-Mesquita HB, Slimani N, Kemper HC, Collette HJ. Relative validity and repeatability of a new questionnaire on physical activity. Prev Med 1997;26(1):37-43.

[16] Roeykens J, Rogers R, Meeusen R, Magnus L, Borms J, de Meirleir K. Validity and reliability in a Flemish population of the WHOMONICA Optional Study of Physical Activity Questionnaire. Med Sci Sports Exerc 1998;30(7):1071-5.

[17] Suzuki I, Kawakami N, Shimizu H. Reliability and validity of a questionnaire for assessment of energy expenditure and physical activity in epidemiological studies. J Epidemiol 1998;8(3):152-9.

[18] Philippaerts RM, Westerterp KR, Lefevre J. Doubly labelled water validation of three physical activity questionnaires. Int J Sports Med 1999; 20(5):284-9.

[19] Miller DJ, Freedson PS, Kline GM. Comparison of activity levels using the Caltrac accelerometer and five questionnaires. Med Sci Sports Exerc 1994;26(3):376-82.

[20] Melanson EL, Freedson PS. Validity of the Computer Science and Applications, Inc. (CSA) activity monitor. Med Sci Sports Exerc 1995; 27(6):934-40.

[21] Kemper HCG, Ooijendijk WTM, Stiggelbout M. Consensus about the Dutch physical activity guideline. Tijdschr Soc Geneeskd 2000;78(3): $180-3$. 